\title{
Article
}

\section{Adsorption of phosphate by halloysite (7 $\AA$ ) nanotubes (HNTs)}

\author{
Nia Gray-Wannell1,2 (D), Peter J. Holliman², H. Christopher Greenwell ${ }^{3}$, Evelyne Delbos ${ }^{1}$ and Stephen Hillier ${ }^{1,4 *}$ \\ ${ }^{1}$ The James Hutton Institute, Craigiebuckler, Aberdeen, AB15 8QH, UK; ${ }^{2}$ Chemical Engineering Materials Environment Group, Swansea University, Bay Campus, \\ Swansea, SA1 8EN, UK; ${ }^{3}$ Department of Earth Sciences, Durham University, Durham, DH1 3LE, UK and ${ }^{4}$ Department of Soil and Environment, Swedish University of \\ Agricultural Sciences, PO Box 7014, SE-75007 Uppsala, Sweden
}

\begin{abstract}
The adsorption and retention of phosphates in soil systems is of wide environmental importance, and understanding the surface chemistry of halloysite (a common soil clay mineral) is also of prime importance in many emerging technological applications of halloysite nanotubes (HNTs). The adsorption of phosphate anions on tubular halloysite ( $7 \AA$ ) has been studied to gain a greater understanding of the mechanism and kinetics of adsorption on the surface of HNTs. Two well-characterized tubular halloysites with differing morphologies have been studied: one polygonal prismatic and one cylindrical, where the cylindrical form has a greater surface area and shorter tube length. Greater phosphate adsorption of up to $42 \mu \mathrm{mol} \mathrm{g}{ }^{-1}$ is observed on the cylindrical halloysite when compared to the polygonal prismatic sample, where adsorption reached a maximum of just $15 \mu \mathrm{mol} \mathrm{g} \mathrm{g}^{-1}$ compared to a value for platy kaolinite (KGa-2) of $8 \mu \mathrm{mol} \mathrm{g}$. Phosphate adsorption shows strong $\mathrm{pH}$ dependence, and the differences in phosphate sorption between the prismatic and cylindrical morphologies suggest that phosphate absorption does not occur at the same $\mathrm{pH}$-dependent alumina edge sites and that the lumen may have a greater influence on uptake for the cylindrical form.
\end{abstract}

Keywords: adsorption, anion-exchange capacity, halloysite nanotube, HNT, phosphate

(Received 9 January 2020; revised 7 April 2020; Accepted Manuscript online: 6 August 2020; Associate Editor: Balwant Singh)

Phosphorus is an essential element in agriculture, and its deficiency can limit terrestrial plant growth (Vitousek \& Howarth, 1991; Smith et al., 1999). As a result, phosphate is applied globally in fertilizers. In recent years, the use of phosphate fertilizers has increased significantly in Asia (Lu \& Tian, 2017), but decreased in Europe, the latter due, in part, to concern over watercourse pollution. Leaching of excess phosphorus from soil into groundwater either as orthophosphate, organic and inorganic phosphorus or soluble mineral species can result in significant environmental problems such as eutrophication (Weng et al., 2012). Further detrimental consequences including loss of aquatic life, increased algal blooms and oxygen depletion of the water, amongst others (Carpenter et al., 1998), often result. Excessive phosphorus use can therefore threaten environmental systems whilst increasing the risk of shortages of this finite resource - with recent estimates warning of a rapid depletion of economic sources of phosphorus over the next century (Oelkers \& Valsami-Jones, 2008).

Sorption of phosphate by clay minerals plays a key role in determining phosphorus availability in the soil system (Gustafsson et al., 2012; Gérard, 2016). As halloysite is found in soils worldwide, especially in tropical soils (White \& Dixon, 2002), an understanding of the conditions of adsorption of phosphate onto the halloysite surface is needed. Additionally, the increasing use of halloysite in many emerging technologies

${ }^{*}$ E-mail: stephen.hillier@hutton.ac.uk

Cite this article: Gray-Wannell N, Holliman PJ, Greenwell HC, Delbos E, Hillier S (2020). Adsorption of phosphate by halloysite (7 ̊̊) nanotubes (HNTs). Clay Minerals 55, 184-193. https://doi.org/10.1180/clm.2020.24 requires an improved understanding of the surface chemistry of halloysite beyond the currently simplistic models that are usually assumed. In this context, the adsorption behaviour of the phosphate anion is a useful reference molecular probe of the surface chemistry characteristics of halloysite nanotubes.

The mineral halloysite was first reported by Berthier (1826). Halloysite is a member of the kaolin group or subgroup of minerals and, in its fully hydrated state, it has the ideal unit formula $\mathrm{Al}_{2} \mathrm{Si}_{2} \mathrm{O}_{5}(\mathrm{OH})_{4} \cdot 2 \mathrm{H}_{2} \mathrm{O}$. It is found in rocks and soils worldwide and can occur naturally in a variety of morphologies, the most common being tubular (Joussein et al., 2005). In recent years, the tubular form of halloysite nanotubes (HNTs), with their nanoscale central lumen (Fig. 1c), along with other useful physical and chemical properties such as high length to diameter ratio and lack of toxicity (Vergaro et al., 2010; Fakhrullina et al., 2015; dos Santos et al., 2017), have been central to halloysite's increasing application in existing and emerging technologies such as drug-delivery systems, polymer nanocomposites (Massaro et al., 2017), flame-retardant materials and batteries (Lin et al., 2017), amongst many others (Yuan et al., 2015). Often, especially in studies of the application of halloysite in new technologies, a rather simplistic view of the halloysite structure is adopted that depicts a uniform and continuous outer siloxane surface and an inner aluminol surface, as shown in Fig. 1 (Yuan et al., 2015; Kim et al., 2017; Rostamzadeh et al., 2017). Furthermore, these two surfaces are often labelled as distinctly charged, with the outer siloxane surface exclusively negatively charged and the inner aluminol surface positively charged (Bretti et al., 2016; Massaro et al., 2017). Studies on the surface

(C) The Author(s), 2020. Published by Cambridge University Press on behalf of The Mineralogical Society of Great Britain and Ireland. This is an Open Access article, distributed under the terms of the Creative Commons Attribution licence (http://creativecommons.org/licenses/by/4.0/), which permits unrestricted re-use, distribution, and reproduction in any medium, provided the original work is properly cited. 
(a)

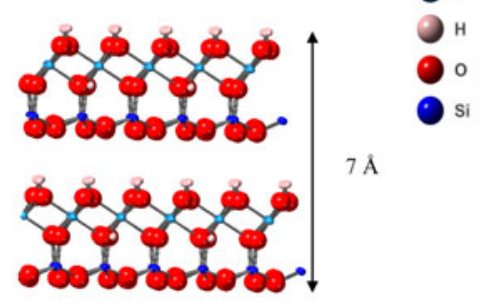

(b)

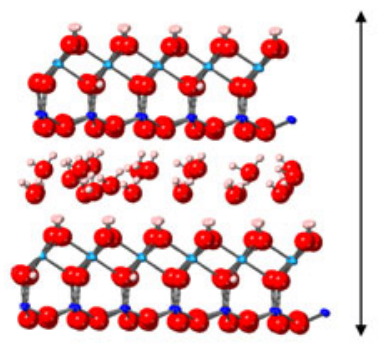

(c)

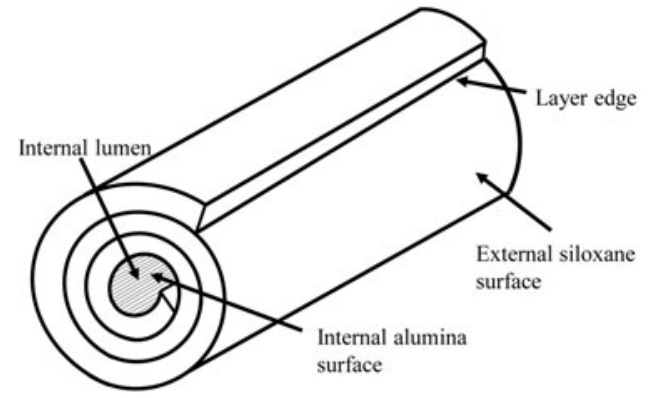

Fig. 1. (a) Halloysite $7 \AA$ structure, (b) halloysite $10 \AA$ structure and (c) schematic diagram of a HNT.

charge of kaolinites have highlighted two distinct sources of charge: the in-plane basal sites in the tetrahedral sheet and the edge sites of both the octahedral and tetrahedral sheets, where charge is $\mathrm{pH}$ dependent (Zhou \& Gunter William, 1992; Brady et al., 1996; Gu \& Evans, 2008). The permanent charge on the siloxane sheet arises due to isomorphic substitution of $\mathrm{Al}^{3+} / \mathrm{Fe}^{3+}$ for $\mathrm{Si}^{4+}$. However, Sposito (1984) suggests that the charge of the siloxane basal sheets is negligible because the degree of ionic substation is very small; indeed, he estimated the layer charge at $<0.01$ per $\left[\left(\mathrm{Si}_{4}\right)\left(\mathrm{Al}_{4}\right) \mathrm{O}_{10}(\mathrm{OH})_{8}\right]$ formula unit. The hydroxyl edge sites of both the alumina and siloxane sheets are proton donor groups that can form complexes with metal cations. In comparison, for anion adsorption, silanol groups have a $\mathrm{pKa}_{(\mathrm{int})}$ of 8.23 compared to that of the aluminol edge sites $(\mathrm{pKa}=5.28)$ (Brady et al., 1996); hence, only the aluminol moieties $(\mathrm{Al}-\mathrm{OH})$ can act as proton acceptor groups. These protonated aluminol sites have been shown to be the sites of anion adsorption in kaolin group minerals (Theng et al., 1982; Van Emmerik et al., 2007; Han et al., 2016).

Whilst kaolinite has been studied regularly for its phosphate adsorption properties (Edzwald et al., 1976; He et al., 1997; Gimsing \& Borggaard, 2002; Kamiyango et al., 2009; Gérard, 2016), there is surprisingly little published work on halloysite (7 $\AA$ ). Very recent work that has investigated halloysite has found adsorption capacities of $1.5 \mathrm{mg} \mathrm{g}^{-1}$ for phosphate after $3 \mathrm{~h}$ equilibrium time (Almasri et al., 2019), whilst Saki et al. (2019) reported that granular halloysite adsorbs more phosphate than powdered halloysite due to the availability of pore space, with a maximum adsorption of $\sim 1.2 \mathrm{mg} \mathrm{g}^{-1}$ phosphate.

A study by Theng et al. (1982) highlighted the importance of morphology on adsorption capacity for halloysite when they reported the maximum phosphate adsorption as $10 \mu \mathrm{mol} \mathrm{g}^{-1}$ for tubular halloysites and $\leq 50 \%$ of this for spheroidal morphologies, which were interpreted as being due to a paucity of edge sites on the spheroidal forms. Similarly, Singh \& Gilkes (1992) found that soil kaolinite had greater phosphate adsorption capacity than Georgia kaolinite, which was ascribed to the greater surface area of the soil kaolinite and hence a greater number of edge sites. Although as a starting point, the surface properties of halloysite may be considered as similar to those of kaolinite, halloysite is initially formed with an interlayer containing $\mathrm{H}_{2} \mathrm{O}$ molecules, the structural 'memory' of which is likely probably retained long after removal. Hallyosite also possesses curved 1:1 layers and so is inherently more disordered and occurs primarily in nanotubular form compared to the exclusively planar form of kaolinite.

Previous studies have highlighted significant differences in the sorption behaviour of halloysite and kaolinite; for example, the greater cation-exchange capacity (CEC) of halloysite, which
Gray et al. (2016) ascribed to a greater surface area and more available edge sites, whilst in an early study using electrodialysis Schell \& Jordan (1959) found that halloysite had a greater anion-exchange capacity than kaolinite. A study by Tarì et al. (1999) found a greater $\zeta$-potential for halloysites compared to kaolinites, suggesting that the surface chemistry for the two polytypes is different. There has been a number of studies on the removal of phosphates from wastewater systems by materials such as natural and modified zeolites (Uzunova \& Mikosch, 2016; He et al., 2017; Andrés et al., 2018), kaolinite (Kamiyango et al., 2009), goethite (Ioannou et al., 2013; Wei et al., 2014), hematite (Borgaard, 1983) and bentonite systems (Ioannou et al., 2013). The potential use of halloysite for such methods has only recently been considered (Almasri et al., 2019), and as such is identified as an area that requires further work. The current paper aims to document the characteristics of phosphate adsorption on halloysite $(7 \AA)$ nanotubes and to highlight the effects of the varying morphology and surface area of HNTs on the resulting phosphate-adsorption capacity. The study was partly conceived as a complementary study to the work of Gray et al. (2016), which detailed the CEC of some wellcharacterized halloysites. Finally, the results from this study will be compared with previous studies on a variety of minerals as an estimation of their potential use in wastewater remediation.

\section{Materials}

Two well-characterized halloysites (Hillier et al., 2016) were used for this study, one from China (4Ch) and the other from Utah, USA (17US), while the disordered kaolinite KGa-2, available from The Clay Minerals Society Source Clays Repository, was used as a well-studied (He \& Balinger, 1997; Gimsing \& Borggard, 2002; Van Emmerik et al., 2007) reference kaolinite to validate the experimental methods. All three clay samples were sieved to $<53 \mu \mathrm{m}$, Na-saturated with excess $\mathrm{NaCl}$, washed with deionized water until they were salt free, as determined by silver nitrate, and freeze dried. The two halloysite samples were chosen for their differing morphologies, where sample 17US can be described as a predominantly polygonal prismatic (Fig. 2a) halloysite and 4Ch as a cylindrical form (Fig. 2b). Typically, polygonal prismatic nanotubes are longer and wider than cylindrical nanotubes (Hillier et al., 2016), as is shown in Table 1 for the samples used in the present study and as can be seen from the various scale bars in Fig. 2a,b. Additionally, polygonal prismatic forms of halloysite have flat external faces, whilst the external faces of the cylindrical forms are curved. The internal lumen surface of both forms is assumed to be curved and of similar diameter. 
(a)

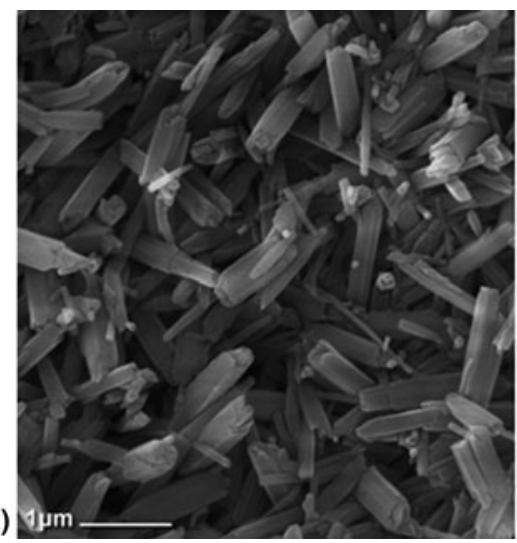

(b)

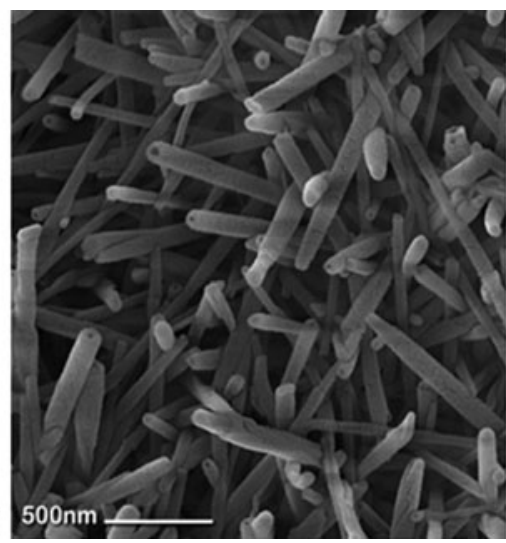

(c)

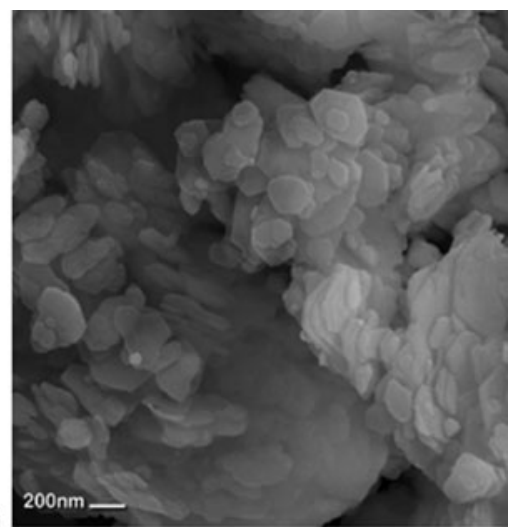

Fig. 2. (a) Polygonal and (b) cylindrical HNTs (Hillier et al., 2016) and (c) KGa-2.

Table 1. Physical properties of the two halloysites and the reference kaolinite.

\begin{tabular}{|c|c|c|c|c|c|c|}
\hline Sample ID & Shape & Mean length (nm) & Mean diameter (nm) & Mean thickness (nm) & $\operatorname{SSA}\left(\mathrm{m}^{2} \mathrm{~g}^{-1}\right)$ & $\operatorname{PZC}(0.1 \mathrm{M} \mathrm{NaCl})(\mathrm{pH})$ \\
\hline $4 \mathrm{Ch}$ & Cylindrical tube & $220^{a}$ & $70^{a}$ & NA & $80^{a}$ & 5.65 \\
\hline 17US & Polygonal tube & $420^{a}$ & $100^{a}$ & NA & $30^{a}$ & 4.85 \\
\hline KGa-2 & Hexagonal plates & NA & $447^{b}$ & $42^{b}$ & $23.5^{c}$ & 5.90 \\
\hline
\end{tabular}

${ }^{a}$ Hillier et al. (2016).

${ }^{b}$ Sutheimer et al. (1999).

c Van Olphen \& Fripiat (1979).

NA: not applicable; SSA: specific surface area; PZC: point of zero charge.

\section{Experimental methods}

Adsorption reactions were conducted to study the effects of $\mathrm{pH}$, varying background electrolyte ionic strength and phosphate concentration on the anion adsorption behaviour of the kaolin group minerals, where the KGa-2 kaolinite sample was used as a reference material only.

\section{Batch equilibrium experiments}

Batch equilibrium systems were set up to measure phosphate adsorption onto the clay minerals. To ensure that the halloysites were dehydrated and in a homogenized state for comparison, $0.1 \mathrm{~g}$ of clay was oven-dried at $105^{\circ} \mathrm{C}$ overnight and mixed with $28 \mathrm{~mL}$ of varying concentrations of background electrolyte, $\mathrm{NaCl}$, ranging from 0.001 to $0.1 \mathrm{M}$. The resulting suspensions were $\mathrm{pH}$ adjusted using $1 \mathrm{~mL}$ of differing concentrations of $\mathrm{HCl}$ (standardized against $\mathrm{Na}_{2} \mathrm{CO}_{3}$ ) or $\mathrm{NaOH}$ (standardized and carbonate free) and shaken for $24 \mathrm{~h}$ in a box shaker. A total of $1 \mathrm{~mL}$ of a known concentration of sodium dihydrogen (ortho)phosphate 1-hydrate was added to the samples, and they were shaken for $16 \mathrm{~h}$ overnight. The initial $\mathrm{P}-\mathrm{PO}_{4}$ concentration ranged from 2.5 to $8.0 \mathrm{mg} \mathrm{L}^{-1}$. The $\mathrm{pH}$ for each sample was measured using a HACH HQ440d pH meter and recorded after 5 min with constant stirring. The samples were centrifuged before filtering through $0.45 \mu \mathrm{m}$ Nylon ${ }^{\otimes}$ filters and stored in a cold room for analysis. Supernatant phosphate concentrations were determined using the molybdenum blue method on a Konelab Discrete Analyser. Dissolved aluminium and silicon in the filtrate were measured by inductively coupled plasma-optical emission spectroscopy (ICP-OES). Each experiment was run in triplicate along with a control blank.

\section{Kinetic experiments}

Halloysite clay $(0.1 \mathrm{~g}$ ) was mixed with $28 \mathrm{~mL}$ of $0.01 \mathrm{M} \mathrm{NaCl}$, the $\mathrm{pH}$ was adjusted using dilute sodium hydroxide resulting in a $\mathrm{pH}$ of $\sim 6$ and the samples were shaken for $24 \mathrm{~h}$. To this, $1 \mathrm{~mL}$ of $\sim 8 \mathrm{mg} \mathrm{L}^{-1}$ phosphate was added, and the samples were shaken for a range of times between $1 \mathrm{~h}$ and 10 days. The $\mathrm{pH}$ was measured before centrifugation and filtration as described in the batch equilibration method. All experiments were conducted in triplicate with control blanks.

\section{Determination of the point of zero charge}

Point of zero charge (PZC) measurements were conducted on the clay materials using the salt addition method (Holliman et al., 2008), wherein 10 aliquots of $0.1 \mathrm{M} \mathrm{NaCl}$ were added to $0.1 \mathrm{~g}$ clay and the initial $\mathrm{pH}$ adjusted to vary from 2 to 11 using $\mathrm{HCl}$ and $\mathrm{NaOH}$. Samples were again prepared in triplicate and mixed thoroughly for $24 \mathrm{~h}$ in a box shaker, with the final $\mathrm{pH}$ measured after $24 \mathrm{~h}$. The difference between the initial and final $\mathrm{pH}(\Delta \mathrm{pH})$ was plotted against the initial $\mathrm{pH}$. The $\mathrm{PZC}$ is described as the point at which the $\mathrm{pH}$ does not change from the initial $\mathrm{pH}$. This method was chosen from the various options available because it operates by saturating the surface with $\mathrm{Na}^{+}$and $\mathrm{Cl}^{-}$ions at various initial $\mathrm{pH}$ values and measuring the change in $\mathrm{pH}$ as the surface ions rearrange themselves. Thus, it relies upon a dynamic surface rearrangement of ions in aqueous solution, which is directly analogous to the phosphate-sorption processes subsequently measured. 


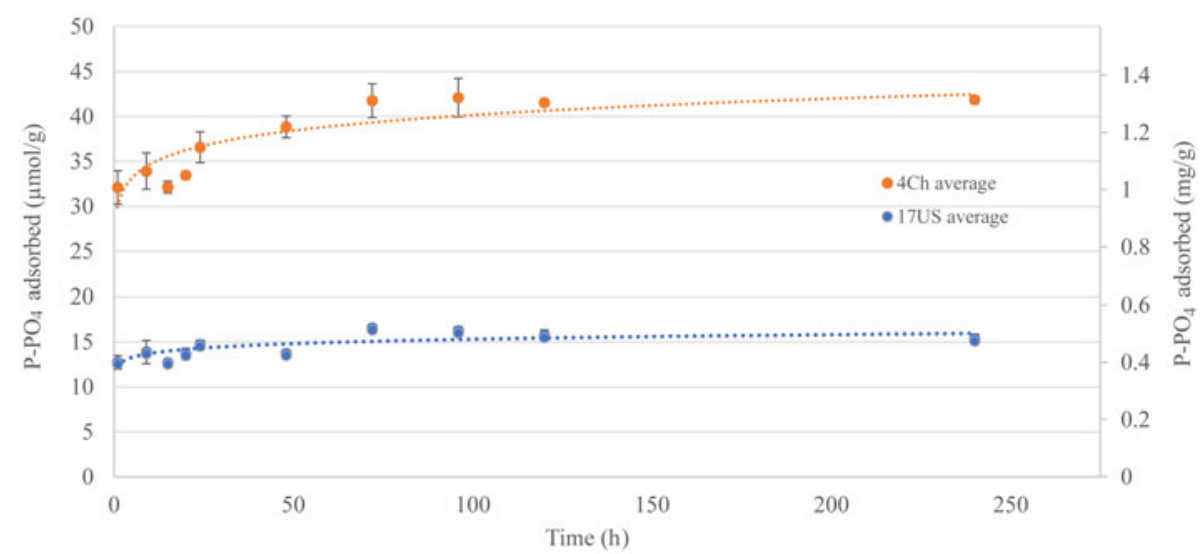

Fig. 3. Kinetics of $\mathrm{P}^{-} \mathrm{PO}_{4}$ adsorption for $17 \mathrm{US}$ and $4 \mathrm{Ch}$ halloysite.
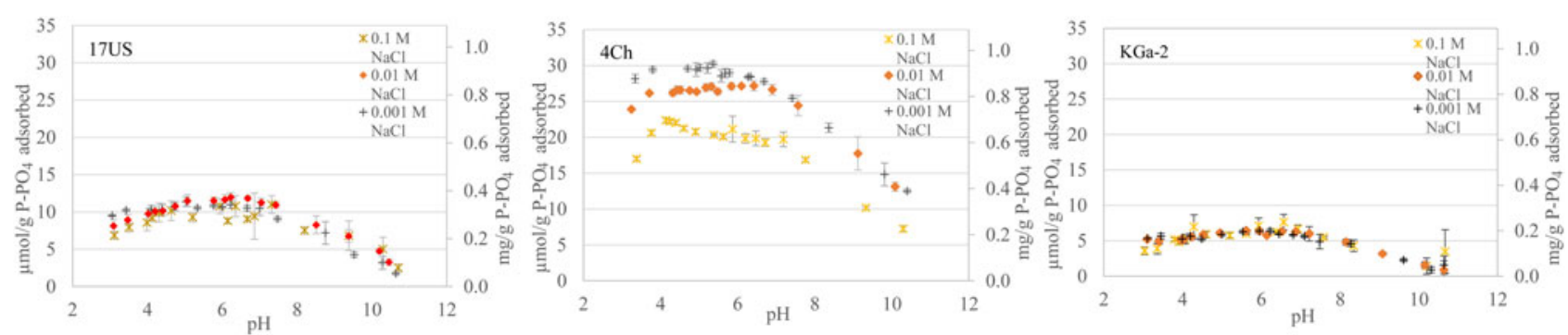

Fig. 4. The effect of background electrolyte ionic strength on $\mathrm{P}_{-} \mathrm{PO}_{4}$ adsorption. Error bars represent the standard deviation of three repeated experiments.
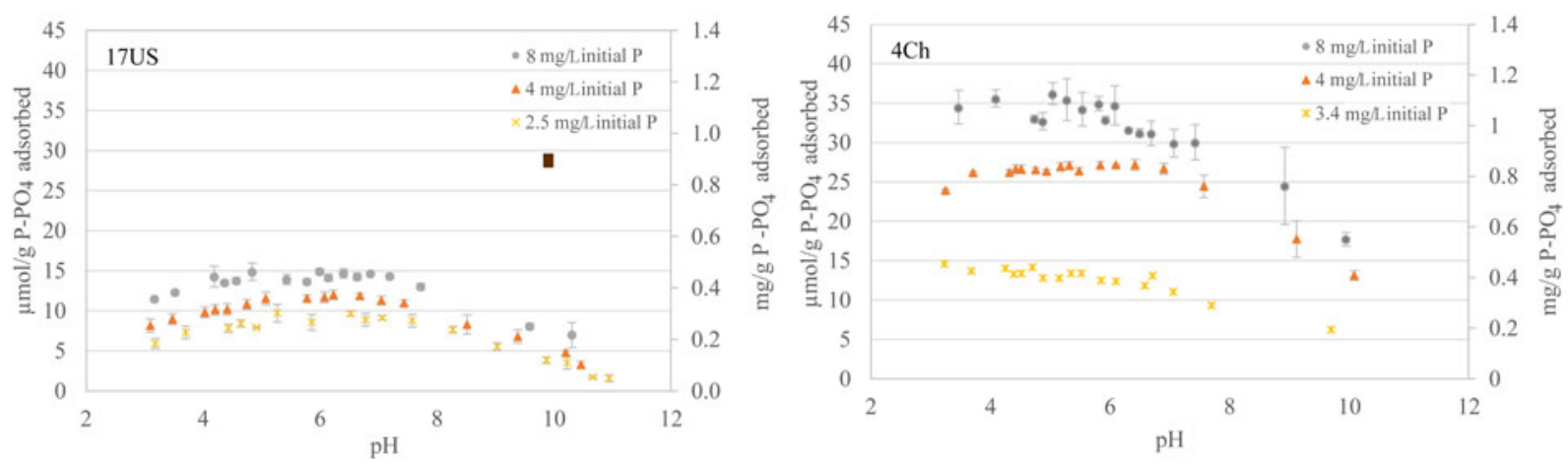

Fig. 5. Effect of $\mathrm{P}_{-} \mathrm{PO}_{4}$ loading. Where shown, error bars represent the standard deviation of three repeated experiments

\section{Fourier-transform infrared spectroscopy}

Hand-ground samples were oven dried at $105^{\circ} \mathrm{C}$ over 2 days and infrared spectra were measured on a Bruker Vertex 70 Fourier-transform infrared (FTIR) spectrometer in the midinfrared region from 4000 to $400 \mathrm{~cm}^{-1}$ with 200 scans taken per spectrum. A germanium disc was used to reduce the penetration depth into the sample in order to see more clearly the changes on the HNT surface. The FTIR spectrometer was dry-air purged to prevent interference in the spectra from water vapour and carbon dioxide.

\section{Results}

\section{Kinetic studies}

The results of the kinetic experiments show that adsorption occurs very rapidly, within hours (Fig. 3; the data are fitted with a trend line for clarity). The batch adsorption experiments for this study were therefore conducted after overnight shaking. From Fig. 3, it is apparent that the cylindrical halloysite (4Ch) displays the greatest phosphate adsorption $\left(\sim 42 \mu \mathrm{mol} \mathrm{g}{ }^{-1}: 1.3 \mathrm{mg} \mathrm{g}^{-1}\right)$ compared to the polygonal prismatic 17US halloysite, which showed less than half this level of adsorption $\left(\sim 15 \mu \mathrm{mol} \mathrm{g}^{-1}: 0.5 \mathrm{mg} \mathrm{g}^{-1}\right)$.

\section{Batch experiments}

Figure 4 shows the effect of changing background electrolyte $(\mathrm{NaCl})$ concentration on the anion adsorption where, for each set, the amount of phosphate added was kept constant at $4 \mathrm{mg} \mathrm{L}^{-1}$. From Fig. 4, it is apparent that the materials all display similar adsorption curves with changes in $\mathrm{pH}$, with a maximum adsorption at $\mathrm{pH} \sim 6$. For the two halloysite samples, the amount of phosphate adsorbed is also dependent on the initial concentration of phosphate, with increasing initial $\mathrm{P}_{-} \mathrm{PO}_{4}$ loading promoting 

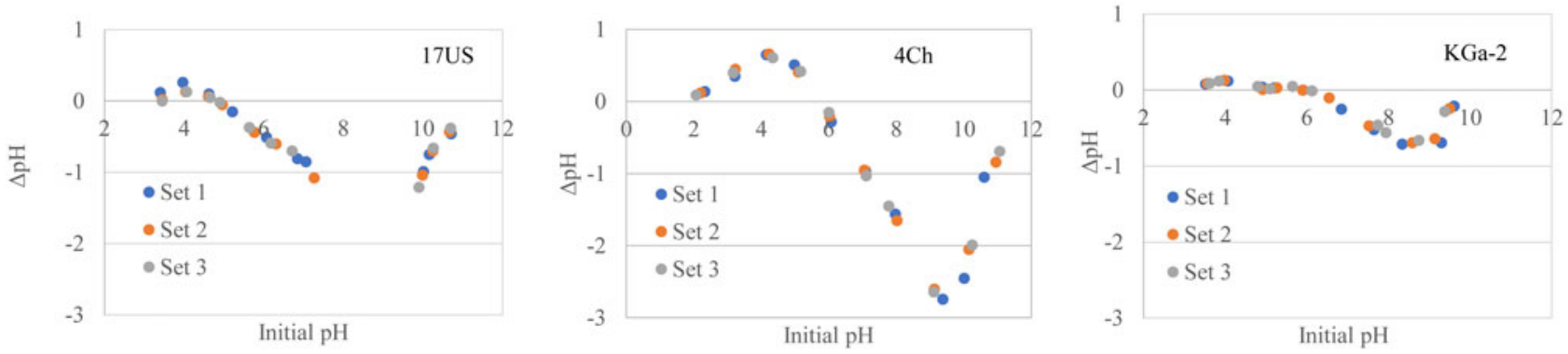

Fig. 6. PZC values for the two halloysites and kaolinite in $0.1 \mathrm{M} \mathrm{NaCl}$. Three replicated sets of measurements were made for each sample.
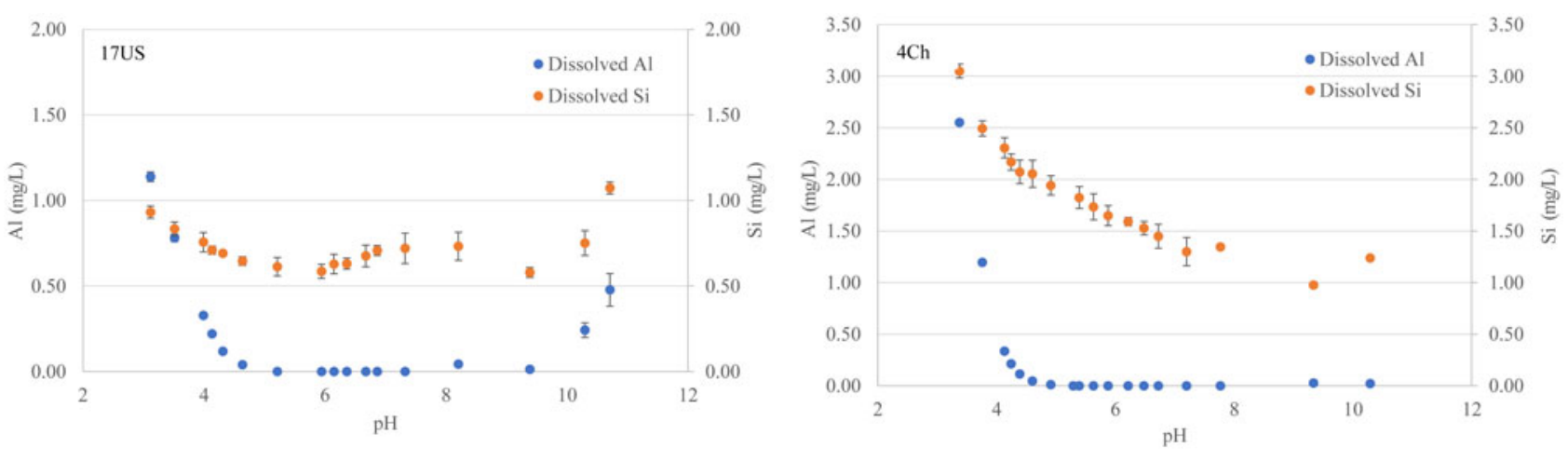

Fig. 7. Dissolved $\mathrm{Al}$ and $\mathrm{Si}$ in $17 \mathrm{US}$ and $4 \mathrm{Ch}$ adsorption reactions over a $\mathrm{pH}$ range of 2-12.

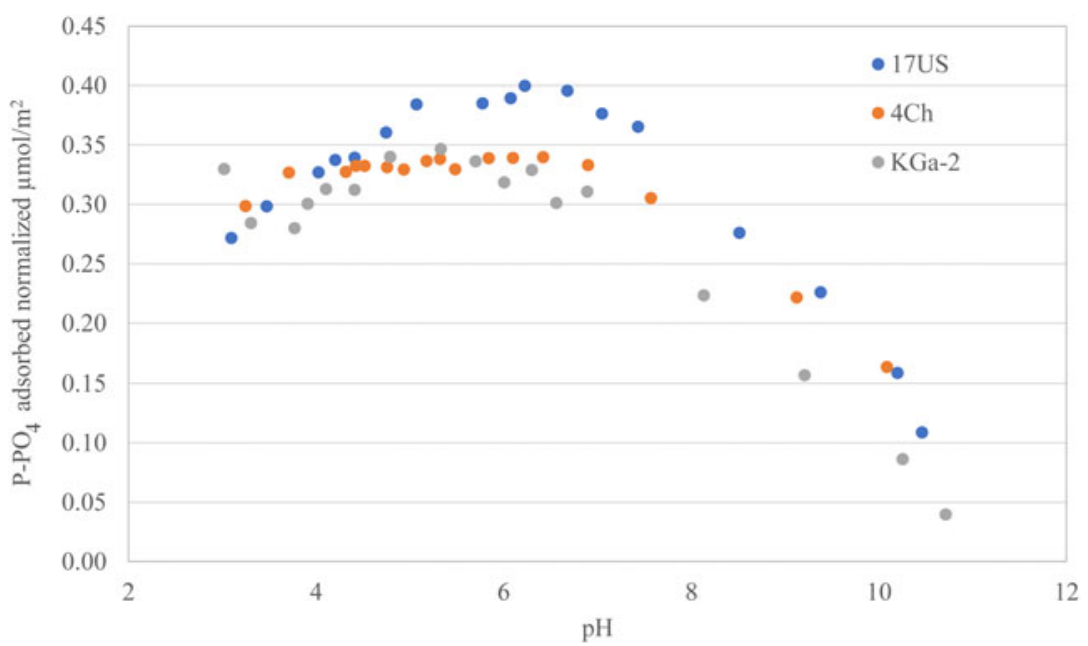

Fig. 8. Phosphate adsorption curves normalized to BET SSA.

increased phosphate adsorption (Fig. 5). In addition, Langmuir adsorption curves were fitted for both samples with varying $\mathrm{P}_{-} \mathrm{PO}_{4}$ concentration at a fixed $\mathrm{pH}$ of 6 . The 17US fits to a linear Langmuir equation, resulting in a potential maximum adsorption of $0.69 \mathrm{mg} \mathrm{g}^{-1}$. The $4 \mathrm{Ch}$ sample did not fit to a Langmuir isotherm (see Figs S2 \& S3).

\section{Point of zero charge}

The PZC is the $\mathrm{pH}$ at which the charge density on the surface of the clay is zero. The PZC graphs for $4 \mathrm{Ch}, 17 \mathrm{US}$ and $\mathrm{KGa}-2$ are provided in Fig. 6. With $0.1 \mathrm{M} \mathrm{NaCl}$, the PZCs determined for 4Ch, 17US and KGa-2 were 5.65, 4.85 and 5.90, respectively (Table 1).

\section{ICP-OES}

The ICP-OES analysis of the remnant solutions across the $\mathrm{pH}$ range from 3 to 10 indicates that below $\mathrm{pH} 4$ the amount of aluminium in the solution increases rapidly (Fig. 7), whilst the silicon in the solution fluctuates across the $\mathrm{pH}$ range.

\section{Effect of morphology on anion adsorption}

In order to determine whether the morphology of the kaolin group minerals affected phosphate adsorption, the measured concentrations of adsorbed phosphate were normalized according to the specific surface area (SSA) of each mineral (Fig. 8). Normalization of the adsorption curves to the SSA indicates 


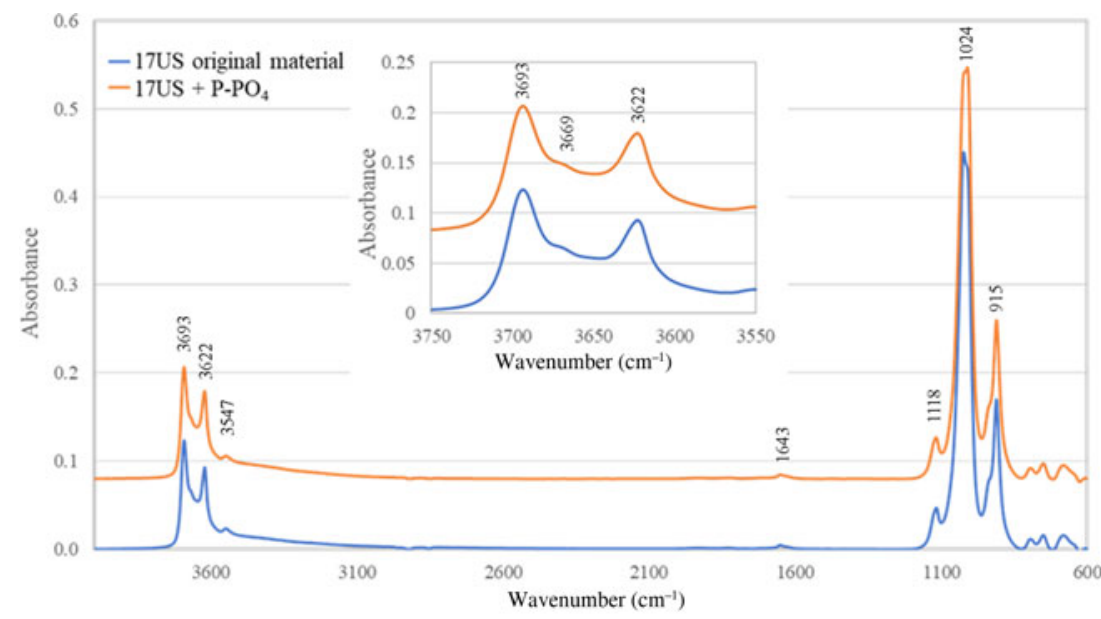

Fig. 9. FTIR spectra of 17US halloysite with and without phosphate adsorption. similar adsorption across the minerals, although the polygonal prismatic halloysite 17US had a slightly greater adsorption of phosphate per $\mathrm{m}^{2}$, particularly between $\mathrm{pH} 5$ and 7 .

\section{FTIR analysis}

The FTIR analysis was conducted to determine the mechanism and sites of adsorption on the HNTs through the comparison of halloysites with and without phosphate adsorption, as presented in Fig. 9. Due to the subtle nature of the changes in the FTIR spectra, the amount of phosphate added to the samples was increased to $215 \mathrm{mg} \mathrm{L}^{-1}$ to saturate the sample in order to obtain clearer results. The magnified inset in Fig. 9 shows the discrete $\mathrm{O}-\mathrm{H}$ stretching bands of the prismatic halloysite with and without phosphate adsorbed, where the intensity of the inner $\mathrm{Al}-\mathrm{OH}$ stretching band at $\sim 3600 \mathrm{~cm}^{-1}$ showed a slight reduction in intensity after phosphate adsorption.

\section{Discussion}

Adsorption is a partitioning process that results in an equilibrium being established between solvated and adsorbed species. This equilibrium can involve positively and negatively charged or potentially neutral species, both in solution and adsorbed to the halloysite surface. However, the nature of the adsorption will be influenced by surface charge because neutral species will most likely physisorb to a surface, which is a lower-energy interaction and can result in desorption. By comparison, charged species are more likely to chemisorb, which will produce a more stable product that is less likely to desorb. In practice, adsorption is dynamic, so adsorbates are likely to adsorb and desorb from a surface until the lowest energy state is reached. Thus, in the context here of charged phosphate ions, charged surface sites are believed to be the most important once equilibrium is reached. If either of these charged surface sites is effectively blocked with the oppositely charged ions, this could reduce uptake of the phosphate anions.

The phosphate adsorption curves with varying $\mathrm{pH}$ for both halloysites and the reference kaolinite all show the same shape, with a maximum at $\mathrm{pH} \sim 6$ and a steady decrease in adsorption with increasing $\mathrm{pH}$ (Figs 4 \& 5). The parabolic shape of the adsorption curves is similar to those seen by other authors studying phosphate adsorption onto kaolinites (e.g. Edzwald et al., 1976; Manning \& Goldberg, 1996). The reduction in adsorption with an increasingly basic solution is in line with the hypothesis that, at greater $\mathrm{pH}$, the edge sites are deprotonated and so display a net negative charge, which could electrostatically repel phosphate anions. The slight decrease in phosphate adsorption below pH 4 may be ascribed to surface protonation, which would produce a net positive surface charge. At lower $\mathrm{pH}$ values, phosphate has a lower charge in solution, which would reduce the attraction between the positive surface charge and negatively charged phosphate ions, resulting in lower adsorption. From the batch adsorption curves (Figs $4 \& 5$ ) and under the experimental conditions outlined, the maximum adsorption for the 17US sample is $0.5 \mathrm{mg} \mathrm{g}^{-1}$, and this value is $1.3 \mathrm{mg} \mathrm{g}^{-1}$ for $4 \mathrm{Ch}$. The amount adsorbed by the cylindrical sample is in line with the values reported recently by Almasri et al. (2019) and Saki et al. (2019). The variable phosphate loading data at $\mathrm{pH} 6$ were fitted to Langmuir adsorption isotherms (Supplementary Figs S2 \& S3), where it was observed that the 17US prismatic sample obtained a good fit to the Langmuir isotherm $\left(R^{2}=0.9677\right)$, whilst the data for the cylindrical $4 \mathrm{Ch}$ did not fit to the Langmuir isotherm $\left(R^{2}=0.3922\right)$. A key feature of the Langmuir isotherm is that it assumes that all sorption sites are identical. The good fit obtained for the prismatic sample may indicate that the sorption is dominated by edge sites alone, whilst the lack of fit for the cylindrical sample suggests the additional importance of another site, the obvious candidate for which is the aluminol surface of the inner lumen, which we would expect to be proportionally more abundant in the smaller nanotubes that characterize the $4 \mathrm{Ch}$ sample.

One of the main assumptions of this adsorption method is that the phosphate remaining in solution is free and available to react with the surface of the mineral. However, at low $\mathrm{pH}$, dissolved aluminium may form soluble complexes with phosphate. The ICP-OES analysis of the remnant solutions across the $\mathrm{pH}$ range of the PZC experiments shows that at $\mathrm{pH}<4$ the amount of aluminium in solution increases rapidly (Fig. 7). Van Emmerik et al. (2007) studied phosphate adsorption on kaolinite and gibbsite by ${ }^{31} \mathrm{P}$ nuclear magnetic resonance spectroscopy and found evidence of a partially crystalline $\mathrm{AlPO}_{4}$ phase at low $\mathrm{pH}$ values. Those authors inferred that the $\mathrm{Al}-\mathrm{OH}$ edge sites where anion adsorption occurs play a role in the formation of a surface precipitate, which at low $\mathrm{pH}$ values would reduce the number of available sites for anion adsorption. It can be seen from the ICP-OES analysis in this current study that labile $\mathrm{Al}$ is present in solution at these lower $\mathrm{pH}$ values (Fig. 7). The presence of such phases could provide one explanation for the observed reduction in 
phosphate adsorption at lower $\mathrm{pH}$ values. In addition, Huang et al. (2009) proposed a model for Al-oxides that suggested the decrease in phosphate sorption at $\mathrm{pH}<4$ was due to the absence of proton-reactive but phosphate-non-reactive triply coordinated surface hydroxyls in the alumina sheet, and they used these groups to distinguish between $\mathrm{Al}$ - and $\mathrm{Fe}$-oxides and their adsorption curves.

The PZC data show notably similar trends across the three minerals investigated (Fig. 6). Both halloysites and kaolinite show a maximum adsorption at $\mathrm{pH} \sim 6$ (Figs $4 \& 5$ ), which is just above the range of the PZC for these samples (Table 1), with adsorption decreasing at $\mathrm{pH}<4$ or $\mathrm{pH}>8$. One explanation for the change of trend in the $\mathrm{PZC}$ curve at higher and lower $\mathrm{pH}$ values is due to metal ion dissolution at extreme $\mathrm{pH}$, as is expected for amphoteric aluminium oxides and confirmed by the ICP-OES analysis. While there are no reference PZC values for halloysite as far as the authors are aware, the value of 5.9 for kaolinite $\mathrm{KGa}-2$ in $0.1 \mathrm{M} \mathrm{NaCl}$ is slightly higher than previously reported values for kaolinite: $\mathrm{KGa}-2=5.4$ (Schroth \& Sposito, 1997), China kaolinite $=4.1$ (Wei et al., 2014) and Linthipe kaolinite $=5.1$ (Kamiyango et al., 2009). While the $\mathrm{PZC}$ value obtained in this study is slightly higher, it is still considered within the range of literature values, where the variations between reported results may arise due to differences in background ionic strength, kaolinite crystallinity and experimental methods. In the case of the halloysites, the greater $\mathrm{pH}$ for the PZC of the cylindrical 4Ch suggests that it has more positively charged surface sites than the polygonal prismatic 17US sample, which may be explained by the greater surface area of cylindrical halloysites and perhaps a proportionally more important contribution of the lumen aluminol surface. In contrast to the halloysites, where the $\mathrm{PZC}$ is approximately the $\mathrm{pH}$ of the maximum observed phosphate adsorption, the PZC for goethite is $\mathrm{pH} \sim 9$ (Van Emmerik et al., 2007), which is the point at which the adsorption of phosphate on goethite is at its lowest. Consequently, while PZC is an effective measurement for understanding some of the surface chemistry of the mineral, anion adsorption on minerals is not considered to be related to the PZC, but rather is surface-area dependent (Gérard, 2016). This was a key reason why the particular PZC method used in the present investigation was chosen, because it relies on initial chloride anion sorption and effectively measures the change in proton concentration $(\mathrm{pH})$ following the dynamic rearrangement of surface ions over time. Therefore, it was considered the most relevant method for comparison with phosphate sorption.

Kinetic adsorption experiments conducted over a time period of $30 \mathrm{~min}$ to 10 days showed that, for both halloysites, the adsorption of phosphate was rapid and maximum adsorption was obtained between $24 \mathrm{~h}$ for 17US and $48 \mathrm{~h}$ for $4 \mathrm{Ch}$ (Fig. 3). The slower rate of uptake in $4 \mathrm{Ch}$ presumably reflects a combination of its greater phosphate uptake $\left(42 \mu \mathrm{mol} \mathrm{g}^{-1}\right)$ and cylindrical morphology compared to the polygonal prismatic 17US (15 $\mu \mathrm{mol} \mathrm{g}{ }^{-1}$ uptake). At first sight, the 4Ch sample might appear to exhibit slower phosphate diffusion. However, given that it absorbs $>2.5$ times more phosphate than 17US, the specific rate in terms of phosphate uptake per unit time is greater. Interestingly, a slight dip was noted consistently for both halloysites at $\sim 20 \mathrm{~h}$ equilibration time, followed by a recovery that follows the kinetic adsorption curve. While this feature cannot be fully explained without further investigation, we suggest that it may be due some form of rearrangement of phosphate on the surface. As such, here we purposely chose to use $\sim 16 \mathrm{~h}$ for the sorption experiments, in line with previous adsorption experiments on halloysite (Theng et al., 1982). In practice, this was a compromise with the aim of minimizing multilayer sorption in $4 \mathrm{Ch}$ whilst the 17US sample had reached $90 \%$ of total uptake. Typically, adsorption experiments have been considered to be at equilibrium within $24 \mathrm{~h}$ (Theng et al., 1982; Ioannou \& Dimirkou, 1997), and continued reaction times could result in further sorption processes such as multilayer adsorption or, after periods of several days to a few weeks, surface precipitation (Gérard, 2016). This is in contrast with other non-clay materials such as industrial by-products, where Habibiandehkordi et al. (2014) showed that a minimum equilibration period of 5 days is required for maximum phosphate adsorption.

The difference in adsorption capacity at fixed initial phosphate concentrations between the cylindrical and prismatic halloysite is shown in the kinetic adsorption experiments (Fig. 3), where the cylindrical halloysite has an adsorption $>2.5$ times greater than that of the prismatic halloysite. Previous work has shown that anion adsorption occurs primarily on the $\mathrm{pH}$-dependent edge sites of the HNTs (Theng et al., 1982) and the number of edge sites is related to surface area. Results reported in a study of the CEC of seven different halloysites (Gray et al., 2016) showed that, in general, cylindrical halloysites had a slightly greater CEC than the polygonal prismatic halloysites, although this difference was reduced after normalization to surface area, and the majority of the cation adsorption occurs on the $\mathrm{pH}$-dependent edge sites. Thus, we propose that the difference in adsorption between the two morphologies may be rationalized by considering that the cylindrical HNTs are much smaller with a greater SSA and, hence, more edge sites are available for adsorption reactions and, as discussed above, there is some evidence for a proportionally greater influence of aluminol sites in the lumen. Normalization of the adsorption curves to Brunauer-EmmettTeller (BET) SSA is shown in Fig. 8. The normalized adsorption curves for kaolinite and cylindrical halloysite $4 \mathrm{Ch}$ are closely matched, whilst the prismatic 17US displays a small increase in adsorption levels between $\mathrm{pH} 5$ and 7. The general convergence of the data points after normalization to the SSA effectively demonstrates the importance of this feature on the phosphate adsorption capacity. The slightly elevated levels of phosphate adsorption per $\mathrm{m}^{2}$ for $17 \mathrm{US}$ compared to $4 \mathrm{Ch}$ and $\mathrm{KGa}-2$ could be rationalized by considering that there may be a greater number of steps and edges, and hence reaction sites, on the larger prismatic tubes of 17US halloysite. Further work, such as atomic force microscopy studies, are in progress to investigate this possibility.

Hayes \& Leckie (1987) advised that studying the effects of electrolyte ionic strength on adsorption reactions can result in identifying the adsorption mechanism as either inner-sphere (chemisorbed) or outer-sphere (physisorbed), where outer-sphere reactions are shown to be affected by competition with a high ionic strength background electrolyte. He et al. (1997) studied phosphate adsorption onto kaolinite (KGa-2) with varying ionic strengths and noted that the ionic strength had little effect on phosphate adsorption; rather, it was $\mathrm{pH}$ that had the most significant effect. From Fig. 4, there appear to be few to no competing effects from the sodium chloride with regards to the phosphate adsorption, except in the case of the cylindrical $4 \mathrm{Ch}$, where the greatest molarity $(0.1 \mathrm{M} \mathrm{NaCl})$ displays a tendency towards generally lower phosphate adsorption for the samples. From this it can be suggested that predominantly inner-sphere chemisorption may be taking place on the positively charged surface sites, although the presence of some outer-sphere physisorption 
Table 2. Phosphate/phosphorus adsorbents.

\begin{tabular}{|c|c|c|c|c|}
\hline Material & $\begin{array}{c}\mathrm{P}^{-} \mathrm{PO}_{4} \text { adsorbed } \\
\left(\mathrm{mg} \mathrm{g}^{-1}\right)^{a}\end{array}$ & $\begin{array}{c}\mathrm{P}^{-\mathrm{PO}_{4}} \text { adsorbed } \\
\text { normalized to SSA } \\
\left(\mathrm{mg} \mathrm{m}^{-2}\right)\end{array}$ & $\begin{array}{l}\text { SSA in literature } \\
\qquad\left(\mathrm{m}^{2} \mathrm{~g}^{-1}\right)\end{array}$ & Reference \\
\hline La-zeolite & 17.20 & 0.326 & 52.75 & He et al. (2017) \\
\hline Zeolite & 0.30 & 0.001 & 243 & Andrés et al. (2018) \\
\hline Montmorillonite & 0.16 & 0.008 & 20 & Gimsing \& Borggaard (2002) \\
\hline Illite & 0.23 & 0.005 & 43 & Gimsing \& Borggaard (2002) \\
\hline Gibbsite & 4.90 & 0.108 & 45 & Gimsing \& Borggaard (2002) \\
\hline Goethite & 5.60 & 0.140 & 40 & Gimsing \& Borggaard (2002) \\
\hline Goethite & 7.10 & 0.210 & 32.70 & Ioannou et al. (2013) \\
\hline Goethite 1 & 3.02 & 0.190 & 16 & Borggaard (1983) \\
\hline Goethite B & 19.19 & 0.230 & 82 & Borggaard (1983) \\
\hline Hematite & 5.27 & 0.380 & 14 & Borggaard (1983) \\
\hline Hematite & 21.56 & 0.340 & 64 & Borggaard (1983) \\
\hline Goethite & 10.00 & 0.195 & 51.24 & Wei et al. (2014) \\
\hline Kaolinite & 1.60 & 0.096 & 16.62 & Wei et al. (2014) \\
\hline Kaolinite (KGa-2) & 0.18 & 0.007 & 23.6 & He et al. (1997) \\
\hline Kaolinite (KGa-2) & 0.33 & 0.015 & 22 & Gimsing \& Borggaard (2002) \\
\hline Soil kaolinite & 0.65 & 0.012 & 53 & Singh \& Gilkes (1992) \\
\hline Cylindrical halloysite (4Ch) & 1.30 & 0.016 & 80 & This study \\
\hline Polygonal prismatic halloysite (17US) & 0.50 & 0.016 & 30 & This study \\
\hline Kaolinite (KGa-2) & 0.27 & 0.011 & 23.5 & This study \\
\hline Granular halloysite & 1.20 & 0.048 & 25 & Saki et al. (2019) \\
\hline Powdered halloysite & $\sim 1.10$ & $\sim 0.044$ & 25 & Saki et al. (2019) \\
\hline Hydrated cylindrical halloysite & 1.30 & 0.015 & 86 & Unpublished - this study, see Supplementary Materials \\
\hline Hydrated prismatic halloysite & 0.35 & 0.006 & 58 & Unpublished - this study, see Supplementary Materials \\
\hline Halloysite + lanthanum oxycarbonate & 130.4 & 2.031 & 64.2 & Wei et al. (2019) \\
\hline
\end{tabular}

${ }^{a}$ Unit conversions assuming ideal chemical formula.

reactions occurring between the mineral and phosphate in solution should not be ruled out.

From the adsorption curves, which show a maximum adsorption at $\mathrm{pH} \sim 6$, and the speciation curve of phosphoric acid (see Supplementary Fig. S1), it is evident that the most likely species of phosphate involved in the adsorption reactions are $\mathrm{H}_{2} \mathrm{PO}_{4}^{-}$and $\mathrm{HPO}_{4}^{2-}$, which are the common forms of labile phosphate in soil systems (Haygarth et al., 2013). At pH values at or below the PZC value, we expect the halloysite surface to be protonated and positively charged, resulting in monodenate and some bidentate phosphate uptake. At $\mathrm{pH}$ values greater than the $\mathrm{PZC}$ value for each halloysite, the surface is likely to be negatively charged, leading to a gradual decrease in phosphate adsorption as the increasingly negatively charged anions are repelled. FTIR analysis was used as a method to try to establish the surface adsorption mechanism. FTIR analysis can be used to differentiate between the two morphologies of halloysite according to their degree of ordering (Hillier et al., 2016). As with kaolinite, the more ordered polygonal prismatic morphologies often have a band at $\sim 3659 \mathrm{~cm}^{-1}$, which, in the case of halloysite, is assigned to out-of-phase Al-OH stretching due to imperfect threefold symmetry (Farmer, 1974).

The FTIR spectra presented in Fig. 9 of both the original 17US sample and 17US with adsorbed phosphate show few visible differences. While the FTIR results are subtle for the polygonal prismatic 17US halloysite, with increased phosphate adsorption the intensity of the inner (Al)O-H stretching band at $\sim 3660 \mathrm{~cm}^{-1}$ was seen to reduce slightly. This agrees with previous studies which suggested that the aluminol edge groups are the sites with anion-exchange potential (Theng et al., 1982; Han et al., 2016). As no change was seen in the FTIR spectra for $4 \mathrm{Ch}$ in the $\mathrm{Al}-\mathrm{OH}$ region before and after phosphate adsorption, the spectra are not presented here. In addition, overlap between the $\mathrm{P}-\mathrm{O}$ stretching bands in the region of $1200-900 \mathrm{~cm}^{-1}$ with the $\mathrm{Si}-\mathrm{O}$ stretching bands in the same region made it difficult to identify the presence of phosphate in this region. Therefore, whilst the FTIR analysis of the prismatic 17US halloysite suggests that the adsorption occurs on the $\mathrm{Al}-\mathrm{OH}$ edge groups, due to their subtle nature, these slight changes in the FTIR spectra (Fig. 9) before and after phosphate adsorption cannot be regarded as fully conclusive.

\section{Use of natural materials as phosphate adsorbents}

Phosphate pollution is of great environmental significance and the use of natural materials as scavengers is widely researched. Multiple studies have been conducted on the removal of phosphates from wastewater systems using materials such as natural and modified zeolites (Uzunova \& Mikosch, 2016; He et al., 2017; Andrés et al., 2018), ochre (Heal et al., 2003), kaolinite (Kamiyango et al., 2009), goethite (Ioannou et al., 2013; Wei et al. 2014) and bentonite systems (Ioannou et al., 2013). The phosphorus/phosphate adsorption capacities of these materials are presented in Table 2. In addition, we conducted phosphate adsorption reactions on hydrated halloysites (Supplementary Figs S4 \& S5), and summary data allow us to conclude that the state of hydration (i.e. 10 vs $7 \AA$ ) does not affect the phosphateadsorption capacity of halloysites, as is shown in Table 2.

While a direct comparison between the studies is not possible due to their different experimental methods and different phosphate loadings, we have normalized the results of each material to their SSA in an attempt to compare the datasets. From this, we can see that the halloysite data generated in this study compared with the data given in Table 2 indicate that HNTs have the potential to adsorb more phosphate than certain montmorillonites, illite and unmodified zeolite. The halloysites are observed to adsorb significantly less phosphate than the Fe-oxide minerals. Despite this, the study conducted here and further studies using modified and unmodified HNTs, as is shown in Table 2, provide evidence that these minerals may contribute to $\mathrm{P}$ removal in soil 
systems and have the potential for use in industrial $\mathrm{P}$ removal when modified.

\section{Conclusion}

This study has investigated the phosphate adsorption capacities of two tubular halloysites and shown that surface area greatly influences the adsorption capacity. Because surface area is correlated with halloysite morphology (cylindrical vs polygonal), cylindrical varieties will generally show greater adsorption than polygonal prismatic halloysites, presumably due to a greater number of edge sites for reaction. However, there is some tentative evidence for an additional, more direct effect of morphology in that the polygonal forms may have more edge sites per unit surface. Additionally, a further difference between the two morphologies in terms of adsorption behaviour was observed in the fitting of the data to Langmuir isotherms, where the prismatic sample obtained a good fit whilst the cylindrical sample did not. This raises the possibility that the two do not adsorb phosphate at the same adsorption sites and that the lumen may have a great influence on adsorption in the cylindrical forms.

The adsorption of phosphate onto kaolin-group clay minerals shows a significant dependency on $\mathrm{pH}$. The maximum adsorption for both halloysites and kaolinite occurs at $\mathrm{pH} \sim 6$, which is slightly greater than their $\mathrm{PZC}$ values and similar to the $\mathrm{pH}$ that would exist in many aquatic and soil systems. This suggests that the halloysites may be able to act as effective phosphate traps or sinks in natural systems. Comparison of the normalized adsorption capacities of halloysites with other clay minerals such as montmorillonite, illite and kaolinite suggests that halloysites have a greater adsorption capacity with respect to phosphate. This contrasts with the adsorption of phosphate by Fe-oxides, which can be seen to be greater than that of clay minerals by a factor of at least 10 .

The relationships between adsorption, morphology and surface area imply that $\mathrm{pH}$-dependent sites must exist on the external surfaces of the HNTs and that the model of the halloysite tubular structure, as is often assumed in technological applications with a uniform external siloxane surface, is too simplistic. Future work will be aimed at more direct ways of examining the surface of HNTs and documenting the true structure of the external surface, which is fundamental to understanding the attempts at and results of HNT functionalization in emerging technological applications and the role of halloysite in adsorption processes in soils.

Supplementary material. To view supplementary material for this article, please visit https://doi.org/10.1180/clm.2020.24.

Acknowledgements. Tony Fraser is acknowledged for his guidance on the FTIR spectra.

Financial support. The Macaulay Development Trust and Swansea University College of Engineering are acknowledged for their $\mathrm{PhD}$ funding of NG-W. SH and NG-W acknowledge the support of the Scottish Government's Rural and Environment Science and Analytical Services (RESAS).

\section{References}

Almasri D.A., Saleh N.B., Atieh M.A., McKay G. \& Ahzi S. (2019) Adsorption of phosphate on iron oxide doped halloysite nanotubes. Scientific Reports, 9 , 3232.
Andrés E., Araya F., Vera I., Pozo G. \& Vidal G. (2018) Phosphate removal using zeolite in treatment wetlands under different oxidation-reduction potentials. Ecological Engineering, 117, 18-27.

Berthier P. (1826) Analyse de l'halloysite. Annales de Chimie et de Physique, 32, 332-335.

Borggaard O.K. (1983) Effects of surface area and mineralogy of iron oxides on their surface charge and anion-adsorption properties. Clays and Clay Minerals, 31, 230-232.

Brady P.V., Cygan R.T. \& Nagy K.L. (1996) Molecular controls on kaolinite surface charge. Journal of Colloid and Interface Science, 183, 356-364.

Bretti C., Cataldo S., Gianguzza A., Lando G., Lazzara G., Pettignano A. \& Sammartano S. (2016) Thermodynamics of proton binding of halloysite nanotubes. Journal of Physical Chemistry C, 120, 7849-7859.

Carpenter S.R., Caraco N.F., Correll D.L., Howarth R.W., Sharpley A.N. \& Smith V.H. (1998) Nonpoint pollution of surface waters with phosphorus and nitrogen. Ecological Applications, 8, 559-568.

dos Santos E.C., Rozynek Z., Hansen E.L., Hartmann-Petersen R., Klitgaard R.N., Løbner-Olesen A. et al. (2017). Ciprofloxacin intercalated in fluorohectorite clay: identical pure drug activity and toxicity with higher adsorption and controlled release rate. RSC Advances, 7, 26537-26545.

Edzwald J.K., Toensing D.C. \& Leung M.C.-Y. (1976) Phosphate adsorption reactions with clay minerals. Environmental Science \& Technology, 10, 485-490.

Farmer V.C. \& Farmer V.C. (1974) The layer silicates. Pp. 340-341 in: The Infrared Spectra of Minerals, 4. Mineralogical Society of Great Britain and Ireland, London, UK.

Gérard F. (2016) Clay minerals, iron/aluminum oxides, and their contribution to phosphate sorption in soils - a myth revisited. Geoderma, 262, 213-226.

Fakhrullina G.I., Akhatova F.S., Lvov Y.M. \& Fakhrullin R.F. (2015) Toxicity of halloysite clay nanotubes in vivo: a caenorhabditis elegans study. Environmental Science: Nano, 2, 54-59.

Gimsing A.L. \& Borggaard O.K. (2002) Competitive adsorption and desorption of glyphosate and phosphate on clay silicates and oxides. Clay Minerals, 37, 509-515.

Gray N., Lumsdon D.G. \& Hillier S. (2016) Effect of $\mathrm{pH}$ on the cation exchange capacity of some halloysite nanotubes. Clay Minerals, 51, 373-383.

Gu X.Y. \& Evans L.J. (2008) Surface complexation modelling of Cd(II), Cu(II), $\mathrm{Ni}(\mathrm{II}), \mathrm{Pb}(\mathrm{II})$ and $\mathrm{Zn}(\mathrm{II})$ adsorption onto kaolinite. Geochimica et Cosmochimica Acta, 72, 267-276.

Gustafsson J.P., Mwamila L.B. \& Kergoat K. (2012) The pH dependence of phosphate sorption and desorption in Swedish agricultural soils. Geoderma, 189, 304-311.

Habibiandehkordi R., Quinton J.N. \& Surridge B.W.J. (2014) Effect of equilibration time on estimates of the maximum phosphorus sorption capacity of industrial by-products using the Langmuir model. Journal of Soils and Sediments, 14, 1818-1828.

Han Y., Liu W., Zhou J. \& Chen J. (2016) Interactions between kaolinite AlOH surface and sodium hexametaphosphate. Applied Surface Science, 387, 759-765.

Hayes K.F. \& Leckie J.O. (1987) Modeling ionic strength effects on cation adsorption at hydrous oxide/solution interfaces. Journal of Colloid and Interface Science, 115, 564-572.

Haygarth P.M., Bardgett R.D. \& Condron L.M. (2013) Phosphorus and nitrogen cycles and their management. Pp. 132-158 in: Russell's Soil Conditions and Plant Growth (12th edition). Longman Scientific and Technical, Harlow, UK.

He L.M., Zelazny L.W., Martens D.C., Baligar V.C. \& Ritchey K.D. (1997) Ionic strength effects on sulfate and phosphate adsorption on $\gamma$-alumina and kaolinite: triple-layer model. Soil Science Society of America Journal, 61, 784-793.

He Y., Lin H., Dong Y. \& Wang L. (2017) Preferable adsorption of phosphate using lanthanum-incorporated porous zeolite: characteristics and mechanism. Applied Surface Science, 426, 995-1004.

Heal K.V., Younger P.L., Smith K.A., Glendinning S., Quinn O. \& Dobbie K.E. (2003) Novel use of ochre from mine waste treatment plants to reduce point and diffuse phosphorus pollution. Land Contamination and Reclamation, $11,145-152$.

Hillier S., Brydson R., Delbos E., Fraser T., Gray N., Pendlowski H. et al. (2016) Correlations among the mineralogical and physical properties of halloysite nanotubes (HNTs). Clay Minerals, 51, 325-350. 
Holliman P.J., Vaca Velasco B., Butler I., Wijdekop M. \& Worsley D.A. (2008) Studies of dye sensitisation kinetics and sorption isotherms of Direct Red 23 on titania. International Journal of Photoenergy, 2008, 827605.

Huang X., Foster G.D., Honeychuck R.V. \& Schreifels J.A. (2009) The maximum of phosphate adsorption at $\mathrm{pH} 4.0$ : why it appears on aluminum oxides but not on iron oxides. Langmuir, 25, 4450-4461.

Ioannou A. \& Dimirkou A. (1997) Phosphate adsorption on hematite, kaolinite, and kaolinite-hematite $(\mathrm{k}-\mathrm{h})$ systems as described by a constant capacitance model. Journal of Colloid and Interface Science, 192, 119-128.

Ioannou Z., Dimirkou A. \& Ioannou A. (2013) Phosphate adsorption from aqueous solutions onto goethite, bentonite, and bentonite-goethite system. Water, Air, \& Soil Pollution, 224, 1374.

Joussein E., Petit S., Churchman J., Theng B., Righi D. \& Delvaux B. (2005) Halloysite clay minerals - a review. Clay Minerals, 40, 383-426.

Kamiyango M.W., Masamba W.R.L., Sajidu S.M.I. \& Fabiano E. (2009) Phosphate removal from aqueous solutions using kaolinite obtained from Linthipe, Malawi. Physics and Chemistry of the Earth, Parts $A / B / C, 34$, 850-856.

Kim T., Kim S., Lee D.K., Seo B. \& Lim C.-S. (2017) Surface treatment of halloysite nanotubes with sol-gel reaction for the preparation of epoxy composites. RSC Advances, 7, 47636-47642.

Lin Y., Wang X., Liu J. \& Miller J.D. (2017) Natural halloysite nano-clay electrolyte for advanced all-solid-state lithium-sulfur batteries. Nano Energy, 31, 478-485.

Lu C. \& Tian H. (2017) Global nitrogen and phosphorus fertilizer use for agriculture production in the past half century: shifted hot spots and nutrient imbalance. Earth System Science Data, 9, 181-192.

Manning B.A. \& Goldberg S. (1996) Modeling arsenate competitive adsorption on kaolinite, montmorillonite and illite. Clays and Clay Minerals, 44, 609-623.

Massaro M., Lazzara G., Milioto S., Noto R. \& Riela S. (2017) Covalently modified halloysite clay nanotubes: synthesis, properties, biological and medical applications. Journal of Materials Chemistry B, 5, 2867-2882.

Oelkers E.H. \& Valsami-Jones E. (2008) Phosphate mineral reactivity and global sustainability. Elements, 4, 83-87.

Rostamzadeh T., Islam Khan M.S., Riche' K., Lvov Y.M., Stavitskaya A.V. \& Wiley J.B. (2017) Rapid and controlled in situ growth of noble metal nanostructures within halloysite clay nanotubes. Langmuir, 33, 13051-13059.

Saki H., Alemayehu E., Schomburg J. \& Lennartz B. (2019) Halloysite nanotubes as adsorptive material for phosphate removal from aqueous solution. Water, 11, 203.

Schell W.R. \& Jordan J.V. (1959) Anion-exchange studies of pure clays. Plant and Soil, 10, 303-318.

Schroth B.K. \& Sposito G. (1997) Surface charge properties of kaolinite. Clays and Clay Minerals, 45, 85-91.
Singh B. \& Gilkes R.J. (1992) Properties of soil kaolinites from south-western Australia. Journal of Soil Science, 43, 645-667.

Smith V.H., Tilman G.D. \& Nekola J.C. (1999) Eutrophication: impacts of excess nutrient inputs on freshwater, marine, and terrestrial ecosystems. Environmental Pollution, 100, 179-196.

Sposito G. (1984) The Surface Chemistry of Soils. Oxford University Press, New York, NY, USA.

Sutheimer S.H., Maurice P.A. \& Zhou Q. (1999) Dissolution of well and poorly crystallized kaolinites; Al speciation and effects of surface characteristics. American Mineralogist, 84, 620-628.

Tari G., Bobos I., Gomes C.S.F. \& Ferreira J.M.F. (1999) Modification of surface charge properties during kaolinite to halloysite- $7 \AA$ transformation. Journal of Colloid and Interface Science, 210, 360-366.

Theng B.K.G., Russell M., Churchman G.J. \& Parfitt R.L. (1982) Surface properties of allophane, halloysite, imogolite. Clays and Clay Minerals, 30, 143-149.

Uzunova E.L. \& Mikosch H. (2016) Adsorption of phosphates and phosphoric acid in zeolite clinoptilolite: electronic structure study. Microporous and Mesoporous Materials, 232, 119-125.

Van Emmerik T.J., Sandström D.E., Antzutkin O.N., Angove M.J. \& Johnson B.B. (2007) ${ }^{31} \mathrm{P}$ solid-state nuclear magnetic resonance study of the sorption of phosphate onto gibbsite and kaolinite. Langmuir, 23, 3205-3213.

van Olphen H. \& Fripiat J.J. (1979) Data Handbook for Clay Materials and Other Non-Metallic Minerals. Pergamon Press, Oxford, UK, and Elmsford, NY, USA.

Vergaro V., Abdullayev E., Lvov Y.M., Zeitoun A., Cingolani R., Rinaldi R. \& Leporatti S. (2010) Cytocompatibility and uptake of halloysite clay nanotubes. Biomacromolecules, 11, 820-826.

Vitousek P.M. \& Howarth R.W. (1991) Nitrogen limitation on land and in the sea: how can it occur? Biogeochemistry, 13, 87-115.

Wei S., Tan W., Liu F., Zhao W. \& Weng L. (2014) Surface properties and phosphate adsorption of binary systems containing goethite and kaolinite. Geoderma, 213, 478-484.

Wei Y., Yuan P., Liu D., Losic D., Tan D., Chen F. et al. (2019) Activation of natural halloysite nanotubes by introducing lanthanum oxycarbonate nanoparticles via co-calcination for outstanding phosphate removal. Chemical Communications, 55, 2110-2113.

Weng L., Van Riemsdijk W.H. \& Hiemstra T. (2012) Factors controlling phosphate interaction with iron oxides. Journal of Environmental Quality, 41, 628-635.

White G.N. \& Dixon J.B. (2002) Kaolin-serpentine minerals. Pp. 389-414 in: Soil Mineralogy with Environmental Applications (J.B. Dixon \& D.G. Schulze, editors). Soil Science Society of America, Madison, WI, USA.

Yuan P., Tan D. \& Annabi-Bergaya F. (2015) Properties and applications of halloysite nanotubes: recent research advances and future prospects. Applied Clay Science, 112-113, 75-93.

Zhou Z. \& Gunter William D. (1992) The nature of the surface charge of kaolinite. Clays and Clay Minerals, 40, 365-368. 